\title{
KESAN KAEDAH MENGAJAR TERHADAP PENCAPAIAN AWAL MATEMATIK DALAM KALANGAN KANAK-KANAK PRASEKOLAH
}

\section{The Effects of Teaching Methods in The Early Mathematics Achievement among Preschool Children}

\author{
Connie Shin @ Connie Cassy Ompok ${ }^{1}$, \& Juppri Bacotang ${ }^{2}$ \\ Fakulti Psikologi dan Pendidikan, Universiti Malaysia Sabah, Kota Kinabalu, Sabah, \\ Malaysia $^{1}$ \\ Fakulti Pembangunan Manusia, Universiti Pendidikan Sultan Idris, Tanjong Malim, Perak, \\ Malaysia $^{2}$
}

connieompok@ums.edu.my ${ }^{1}, \&$ juppri@fpm.upsi.edu.my ${ }^{2}$

DOI: https://doi.org/10.37134/jpak.vol8.2.2019

Received: 14 May 2019; Accepted: 12 November 2019; Published: 23 December 2019

\begin{abstract}
ABSTRAK
Kajian ini bertujuan mengenal pasti kesan kaedah mengajar seperti permainan, buku nombor dan lembaran kerja terhadap pencapaian awal matematik yang merangkumi aras pengetahuan, kefahaman dan aplikasi dalam kalangan kanak-kanak prasekolah. Kajian ini menggunakan pendekatan kuantitatif yang berbentuk kaedah kuasi experimen. Kajian ini melibatkan 1107 orang kanak-kanak prasekolah sebagai sampel, dan menggunakan instrumen Test of Early Mathematics Ability untuk mengumpul data. Data dianalisis melalui statistik deskriptif dan statistik inferensi menggunakan ujian MANCOVA. Dapatan kajian menunjukkan tiga kaedah mengajar, iaitu permainan, buku nombor dan lembaran kerja dapat meningkatkan pencapaian awal matematik kanak-kanak prasekolah. Namun begitu, pengkaji mendapati kaedah mengajar hanya memberi kesan secara signifikan terhadap kefahaman dan analisis awal matematik kanak-kanak prasekolah. Selain itu, kaedah permainan menunjukkan pencapaian awal matematik kanak-kanak prasekolah yang paling tinggi, diikuti dengan kaedah lembaran kerja dan kaedah buku nombor. Justeru, kaedah mengajar yang berteraskan permainan perlu digunakan oleh pendidik dengan sebaik mungkin untuk meningkatkan pencapaian awal matematik kanak-kanak prasekolah.
\end{abstract}

Kata kunci: kaedah mengajar, awal matematik, kanak-kanak prasekolah

\begin{abstract}
This study aims to identify the effects of teaching methods which are games, number books and worksheets towards early mathematics achievement that includes the levels of knowledge, understanding and application among preschool. This study uses a quantitative approach which is a quasi-experimental method. The study involved 1107 preschool as a sample, and used the Test of Early Mathematics Ability instrument to collect data. Data were analyzed through descriptive and inferential statistics using the MANCOVA test.The study found that the three teaching methods which is games, number book and worksheet could increase the early mathematics achievement of preschool. However, researchers had found that the teaching methods only had a significant impact on the understanding and analysis early mathematics of preschool children's. In addition, the game method showed the highest achievement of early mathematics for preschool, followed by worksheets and number books. Therefore, game-based teaching methods should be used by educators as much as possible to improve early mathematics achievement of preschool.
\end{abstract}

Keywords: teaching methods, early mathematics, preschoolers 


\section{PENGENALAN}

Pendidikan awal adalah diperlukan untuk perkembangan kemahiran matematik (Linder, Powers-Costello, \& Stegelin, 2011; Hunting, Mousley, \& Perry, 2012). Lebih-lebih lagi, permulaan yang baik dalam matematik merupakan penentu kepada kejayaan di sekolah rendah, menengah dan peringkat yang lebih tinggi (Duncan et al., 2007). Namun begitu, jurang pencapaian pelajar dalam bidang sains dan matematik di Malaysia masih berada pada tahap yang rendah. Perkara ini jelas terkandung dalam ucapan Chairman of National STEM Movement (Science, Technology, Engineering and Mathematics), Profesor Datuk Dr. Noraini Idris sempena program Saintis Kanak-kanak di Universiti Malaysia Sabah pada 2018, "hanya 19\% daripada 447,000 pelajar yang mengambil mata pelajaran STEM selepas tingkatan tiga". Beliau menegaskan zaman kanak-kanak merupakan masa yang terbaik untuk memperkenalkan STEM.

Walaupun jumlah wang yang banyak telah dilaburkan untuk memajukan pendidikan di Malaysia, prestasi pelajar dalam mata pelajaran matematik telah menunjukkan kemerosotan yang ketara, sedangkan mata pelajaran ini merupakan jalan keluar kepada kejayaan yang lebih tinggi. Menurut Fischetti (2013), ramai kanak-kanak melalui pengalaman sukar dalam awal matematik kerana kaedah mengajar untuk membantu kanak-kanak belajar tidak diketahui dengan jelas. Ini terbukti apabila sangat sedikit kajian yang dijalankan tentang cara yang efektif dalam mengajar matematik (Rohaty, 2012), sedangkan kanak-kanak dilahirkan sebagai pemikir matematik (Geist, 2009). Menurut Smith (2006), mata pelajaran matematik sememangnya sukar dipelajari, namun begitu pendekatan pengajaran yang sesuai diperlukan untuk memperbaiki pencapaian semua kanak-kanak dalam peringkat awal (Clarke, Baker, \& Chard, 2007; Doabler et al., 2011).

Pembelajaran nombor bermula dari operasi pengiraan iaitu yang paling asas (Chin, 2013). Fokus pada peringkat ini bermula dengan kemahiran mengenal, membilang dan mengira angka-angka pada kuantiti yang lebih kecil (Griffin, Case, \& Siegler, 1994). Baroody (1987) menegaskan pembelajaran awal matematik dalam kalangan kanak-kanak berdasarkan kepada konsep perkembangan beransur-ansur yang melibatkan sesuatu penemuan dan pembinaan makna yang lebih mendalam tentang angka dan konsep-konsep pengiraan. Penguasaan pengiraan asas adalah penting bagi membolehkan kanak-kanak menggunakan nombor dengan bebas bagi tujuan operasi berbeza (seperti operasi bahagi dan darab) tanpa perlu untuk sentiasa membuat penghitungan (Chin, 2013).

Walaupun terdapat kajian awal seperti Starkey, Spelke, dan Gelman (1990), dan Wynn (1992) yang membincangkan tentang perkembangan awal kanak-kanak dalam matematik, masih tidak jelas status kemahiran ini sebagai sebahagian daripada kemahiran konseptual atau kemahiran prosedur (Siegler, 2009; Gelman \& Gallistel, 1978). Terma pengetahuan berprosedur dan konsep pengetahuan digunakan dengan meluas dalam penyelidikan pembelajaran matematik (Hiebert \& Lefevre, 1986; Hiebert \& Carpenter, 1992). Menurut Hiebert dan Lefevra (1986), pengetahuan asas tentang bentuk konseptual dan prosedur adalah penting untuk mengetahui cara kanak-kanak belajar membilang dan mengira. Pandangan kedua-dua bidang ilmu ini telah menjadi perbahasan dalam perkembangan pengetahuan awal matematik kanak-kanak. Sebagai contoh, ada pengkaji yang menyatakan kanak-kanak membina prosedur untuk membilang dan mengira berdasarkan prinsip mengira yang mereka tahu (Gelman \& Gallistel, 1978; Gelman \& Meck, 1986). 
Kajian Chin (2013) membincangkan tentang pengetahuan dan pemahaman kanakkanak tentang matematik. Menurutnya, konstruktivis adalah pandangan dunia dalam menyatakan pengetahuan dan dibentuk melalui proses konstruktif aktif murid, manakala kaedah tradisional ialah pengetahuan yang dipindahkan dari guru kepada murid. Kedua-dua pendekatan ini perlu digabungkan, iaitu guru bertindak sebagai mentor yang membimbing kanak-kanak untuk mendapatkan lebih banyak idea matematik (Askew, Brown, Rhodes, Johnson, \& William, 1997). Menurut Chin (2013), individu mempunyai bentuk pemahaman yang berlainan dari pandangan konstruktivis.

Kebanyakan pengkaji bersetuju penggunaan permainan dapat meningkatkan pencapaian mata pelajaran matematik dalam kalangan kanak-kanak (Stannard, Wolfgang, Jones, \& Phelps 2001; Ramani \& Siegler, 2008). Chen dan McNamee (2011) menyatakan permainan merupakan kaedah yang positif dalam meningkatkan pencapaian. Menurut mereka, kanak-kanak yang diberi peluang bermain mempunyai tujuan yang jelas, menggunakan bahan untuk menyelesaikan masalah dan memerlukan tindakan untuk mencapai matlamat, memberi peluang kanak-kanak menghubungkaitkan bahan-bahan permainan dan menyediakan ruang kepada kanak-kanak berimaginasi. Vygotsky (1966) menyatakan permainan kanak-kanak harus berdasarkan kepada perspektif sosio budaya kanak-kanak. Berbanding dengan kajian Thorell, Lindqvist, Nutley, Bohlin dan Klingbert (2009) yang menggunakan kesan latihan dan pemindahan fungsi eksekutif dalam kanak-kanak prasekolah, mereka mendapati bermain permainan yang berulang-ulang boleh meningkatkan ingatan kanak-kanak yang sedang bekerja.

Kajian lepas memberi tumpuan kepada penggunaan buku kanak-kanak untuk mengajar matematik, namun belum banyak bukti empirikal yang dijalankan di luar negara dengan menggunakan kanak-kanak prasekolah sebagai responden. Kajian-kajian empirikal terdahulu yang dijalankan oleh Tare, Chiong, Ganea, dan DeLoache (2010), dan Casey, Erkut, Ceder, dan Young (2008), kaedah mengajar menggunakan buku nombor dijangka menunjukkan kesan yang signifikan terhadap pencapaian awal matematik. Kajian lanjutan adalah diperlukan untuk mengenal pasti kesan penggunaan buku nombor untuk menambahkan lagi bukti empirikal yang sedia ada.

Kajian yang dijalankan oleh Zhou et al. (2006) mendapati kekerapan dan kualiti ibu bapa melibatkan diri dalam aktiviti bersama dengan kanak-kanak di rumah seperti membaca buku dan lembaran kerja matematik diyakini sebagai penyumbang kepada perkembangan matematik kanak-kanak yang lebih baik. Oleh kerana guru prasekolah lebih gemar memilih kaedah lembaran kerja, maka kajian diperlukan untuk mengenal pasti kesan penggunaan kaedah ini dalam pengajaran matematik kanak-kanak. Ransom (2012) menjelaskan penggunaan lembaran kerja membantu pencapaian kanak-kanak. Oleh itu, kaedah mengajar menggunakan lembaran kerja dijangka mempunyai kesan yang signifikan terhadap pencapaian awal matematik kanak-kanak.

Walau bagaimanapun, terdapat beberapa pendapat yang dikemukakan oleh tokoh pendidikan awal kanak-kanak seperti Bowman, Donavan dan Burns (2001), Zigler, Gilliam dan Jones (2006) dan Dunphy (2009) tentang pengajaran yang berkualiti. Menurut mereka, sesuatu program yang menggabungkan pengajaran dan pembelajaran secara kelas, kumpulan kecil dan individu kanak-kanak adalah berhubungan dengan pemerolehan pengetahuan. Koran dan McLaughlin (1990) pula berpendapat semua kaedah mungkin berkesan tetapi membandingkan kaedah yang lebih baik adalah suatu yang signifikan. 
Penyelidikan telah menunjukkan bahawa perkembangan kanak-kanak sangat dipengaruhi oleh faktor-faktor seperti persekitaran, ibu bapa, rakan sebaya dan juga pandangan ibu bapa dalam pendidikan. Memandangkan pengalaman awal persekolahan memainkan peranan penting sebagai asas kemajuan akan datang, kaedah bermain adalah penting kerana ini membolehkan kanak-kanak memanipulasi alat permainan dan melihat keputusannya (Piaget \& Inhelder, 1969). Kaedah bermain antara guru dan kanak-kanak menyediakan persekitaran yang semulajadi dalam membantu perkembangan kanak-kanak (Doig \& Ompok, 2010).

Oleh itu, kajian ini dijalankan untuk mengenal pasti kesan kaedah mengajar seperti permainan, buku nombor dan lembaran kerja terhadap pencapaian awal matematik dalam kalangan kanak-kanak prasekolah.

\section{METODOLOGI}

Pendekatan kajian ini adalah kuantitatif yang menggunakan kaedah kuasi eksperimen. Kajian ini melibatkan 1107 orang kanak-kanak prasekolah sebagai sampel kajian yang dibahagikan kepada tiga kumpulan rawatan mengikut kaedah mengajar, iaitu kumpulan permainan $(\mathrm{N}=382)$, kumpulan buku nombor $(\mathrm{N}=349)$, dan kumpulan lembaran kerja $(\mathrm{N}=377)$.

Intervensi dijalankan oleh guru prasekolah mengikut kaedah mengajar atau kumpulan rawatan yang telah ditetapkan oleh pengkaji. Oleh itu, pengkaji terlebih dahulu menjalankan bengkel kepada guru sebelum pelaksanaan intervensi untuk memastikan semua guru memahami dan cekap dalam menjalankan intervensi seperti yang dikehendaki oleh pengkaji. Intervensi dijalankan selama dua bulan oleh guru di kelas masing-masing dengan menggunakan manual intervensi yang disediakan oleh pengkaji. Pemantauan pelaksanaan intervensi oleh guru juga dijalankan oleh pengkaji dengan mendapat bantuan daripada pembantu penyelidik.

Instrumen Test of Mathematics Ability (Ginsburg \& Baroody, 2003) digunakan semasa ujian pra dan ujian pasca untuk menilai pencapaian awal matematik yang merangkumi aras pengetahuan, kefahaman dan aplikasi dalam kalangan kanak-kanak prasekolah. Data dianalisis melalui statistik deskriptif dan statistik inferensi menggunakan ujian MANCOVA dengan mengawal markah awal matematik kanak-kanak sebelum intervensi (praujian).

\section{DAPATAN KAJIAN}

Jadual 1 menunjukkan nilai min markah awal matematik kanak-kanak (pascaujian), sisihan piawai dan saiz sub-sampel bagi pembolehubah bersandar (pengetahuan, kefahaman dan aplikasi) merentasi kaedah mengajar (permainan, buku nombor, dan lembaran kerja). Pengkaji mendapati kaedah permainan mengatasi kaedah buku nombor, dan kaedah lembaran kerja bagi pencapaian awal matematik yang merangkumi pengetahuan (kaedah permainan $=86.04$, kaedah buku nombor $=83.48$ dan kaedah lembaran kerja $=84.22$ ), kefahaman (kaedah permainan $=72.53$, kaedah buku nombor $=60.22$ dan kaedah lembaran kerja $=63.05$ ), dan aplikasi (kaedah permainan=59.61, kaedah buku nombor=49.83 dan kaedah lembaran kerja=52.45). 
Jadual 1

Min Markah Awal Matematik Kanak-kanak Prasekolah mengikut Kaedah Mengajar (Pascaujian)

\begin{tabular}{llccc}
\hline \multirow{2}{*}{ Awal Matematik } & Kaedah mengajar & $\mathrm{N}$ & Min Markah & $\begin{array}{c}\text { Sisihan } \\
\text { Pengetahuan }\end{array}$ \\
& Permainan & 382 & 86.04 & 16.70 \\
& Buku nombor & 349 & 83.48 & 18.98 \\
& Lembaran kerja & 377 & 84.22 & 19.43 \\
& Jumlah & 1108 & 84.61 & 18.40 \\
\hline Kefahaman & Permainan & 382 & 72.53 & 24.14 \\
& Buku nombor & 349 & 60.22 & 22.41 \\
& Lembaran kerja & 377 & 63.05 & 23.66 \\
& Jumlah & 1108 & 65.43 & 24.01 \\
\hline \multirow{2}{*}{ Aplikasi } & Permainan & 382 & 59.61 & 31.04 \\
& Buku nombor & 349 & 49.83 & 27.30 \\
& Lembaran kerja & 377 & 52.45 & 28.51 \\
& Jumlah & 1108 & 54.09 & 29.31 \\
\hline
\end{tabular}

Jadual 2 menunjukkan keputusan Multivariate Tests $^{a}$, iaitu terdapat kesan pembolehubah tidak bersandar (kaedah mengajar) yang signifikan $[F(6,2206)=12.56$, p<.05], dan terdapat kesan pembolehubah kawalan (praujian) terhadap pembolehubah-pembolehubah bersandar $[F(3,1102)=216.73, \mathrm{p}<.05]$. Berdasarkan keputusan ini, pengkaji mendapati terdapat kesan kaedah mengajar terhadap pengetahuan, kefahaman dan aplikasi bagi pencapaian awal matematik dengan mengawal markah awal matematik kanak-kanak prasekolah sebelum intervensi.

Jadual 2

Keputusan Multivariate Tests ${ }^{a}$

\begin{tabular}{llccccc}
\hline & & \multicolumn{3}{c}{ Hypothesis } \\
& Effect & Value & $F$ & $d f$ & Error df & Sig. \\
\hline \multirow{4}{*}{ Intercept } & Pillai's Trace & .75 & $1093.55^{\mathrm{b}}$ & 3.00 & 1102.00 & .00 \\
& Wilks' Lambda & .25 & $1093.55^{\mathrm{b}}$ & 3.00 & 1102.00 & .00 \\
& Hotelling's Trace & 2.98 & $1093.55^{\mathrm{b}}$ & 3.00 & 1102.00 & .00 \\
& Roy's Largest Root & 2.98 & $1093.55^{\mathrm{b}}$ & 3.00 & 1102.00 & .00 \\
\hline Praujian & Pillai's Trace & .37 & $\mathbf{2 1 6 . 7 3}^{\mathbf{b}}$ & $\mathbf{3 . 0 0}$ & $\mathbf{1 1 0 2 . 0 0}$ & .00 \\
& Wilks' Lambda & .63 & $216.73^{\mathrm{b}}$ & 3.00 & 1102.00 & .00 \\
& Hotelling's Trace & .59 & $216.73^{\mathrm{b}}$ & 3.00 & 1102.00 & .00 \\
& Roy's Largest Root & .59 & $216.73^{\mathrm{b}}$ & 3.00 & 1102.00 & .00 \\
\hline Kaedah & Pillai's Trace & .07 & $\mathbf{1 2 . 5 6}$ & $\mathbf{6 . 0 0}$ & $\mathbf{2 2 0 6 . 0 0}$ & .00 \\
Mengajar & Wilks' Lambda & .93 & $12.75^{\mathrm{b}}$ & 6.00 & 2204.00 & .00 \\
& Hotelling's Trace & .07 & 12.94 & 6.00 & 2202.00 & .00 \\
& Roy's Largest Root & .069 & $25.39^{\mathrm{c}}$ & 3.00 & 1103.00 & .00 \\
\hline
\end{tabular}

a. Design: Intercept $+U P R A+$ Kaedah mengajar

b. Exact statistic

c. The statistic is an upper bound on F that yields a lower bound on the significance level. 
Jadual 3 menunjukkan keputusan Tests of Between-Subjects Effects, iaitu tidak terdapat kesan kaedah mengajar terhadap pencapaian pengetahuan awal matematik $[\mathrm{F}(2,1104)=1.42$, p>.05], terdapat kesan kaedah mengajar terhadap pencapaian kefahaman awal matematik [ $\mathrm{F}(2$, $1104)=30.06, \mathrm{p}<.05]$, dan pencapaian aplikasi awal matematik $[\mathrm{F}(2,1104)=10.18, \mathrm{p}<.05]$ dalam kalangan kanak-kanak prasekolah. Ini bermakna kaedah mengajar hanya memberi kesan secara signifikan terhadap pencapaian kefahaman dan aplikasi awal matematik kanak-kanak prasekolah.

Nilai $\mathrm{R}^{2}$ menunjukkan kaedah mengajar menyumbang sebanyak .297 atau $29.7 \%$ perubahan terhadap pengetahuan, .331 atau $33.1 \%$ perubahan terhadap kefahaman, dan .308 atau $30.8 \%$ perubahan terhadap aplikasi awal matematik kanak-kanak prasekolah.

Jadual 3

Keputusan Tests of Between-Subjects Effects

\begin{tabular}{llccccc}
\hline Source & \multicolumn{1}{c}{$\begin{array}{c}\text { Dependent } \\
\text { Variable }\end{array}$} & $\begin{array}{c}\text { Type III Sum } \\
\text { of Squares }\end{array}$ & Df & $\begin{array}{c}\text { Mean } \\
\text { Square }\end{array}$ & $F$ & Sig. \\
\hline Corrected & Pengetahuan & $111279.75^{\mathrm{a}}$ & 3 & 37093.25 & 155.37 & .00 \\
Model & Kefahaman & $211476.72^{\mathrm{b}}$ & 3 & 70492.24 & 182.47 & .00 \\
& Aplikasi & $293180.82^{\mathrm{c}}$ & 3 & 97726.94 & 164.03 & .00 \\
\hline Intercept & Pengetahuan & 704265.04 & 1 & 704265.04 & 2949.85 & .00 \\
& Kefahaman & 243146.12 & 1 & 243146.12 & 629.40 & .00 \\
& Aplikasi & 62662.62 & 1 & 62662.62 & 105.18 & .00 \\
\hline Praujian & Pengetahuan & 109993.95 & 1 & 109993.95 & 460.72 & .00 \\
& Kefahaman & 180632.08 & 1 & 180632.08 & 467.58 & .00 \\
& Aplikasi & 274173.80 & 1 & 274173.80 & 460.19 & .00 \\
\hline Kaedah & Pengetahuan & $\mathbf{6 7 9 . 2 4}$ & $\mathbf{2}$ & $\mathbf{3 3 9 . 6 2}$ & $\mathbf{1 . 4 2}$ & $\mathbf{. 2 4}$ \\
Mengajar & Kefahaman & $\mathbf{2 3 2 2 3 . 4 7}$ & $\mathbf{2}$ & $\mathbf{1 1 6 1 1 . 7 4}$ & $\mathbf{3 0 . 0 6}$ & $\mathbf{. 0 0}$ \\
& Aplikasi & $\mathbf{1 2 1 3 1 . 4 6}$ & $\mathbf{2}$ & $\mathbf{6 0 6 5 . 7 3}$ & $\mathbf{1 0 . 1 8}$ & $\mathbf{. 0 0}$ \\
\hline Error & Pengetahuan & 263575.60 & 1104 & 238.75 & & \\
& Kefahaman & 426492.38 & 1104 & 386.32 & & \\
& Aplikasi & 657750.58 & 1104 & 595.79 & & \\
\hline Total & Pengetahuan & 8307222.22 & 1108 & & & \\
& Kefahaman & 5381107.27 & 1108 & & & \\
& Aplikasi & 4193140.50 & 1108 & & & \\
\hline Corrected & Pengetahuan & 374855.35 & 1107 & & & \\
& Kefahaman & $\mathbf{6 3 7 9 6 9 . 1 0}$ & 1107 & & & \\
& Aplikasi & 950931.39 & 1107 & & & \\
\hline
\end{tabular}

a. $\boldsymbol{R}$ Squared $=.297$ (Adjusted $R$ Squared $=.295$ )

b. $\boldsymbol{R}$ Squared $=.331$ (Adjusted $R$ Squared $=.330$ )

c. $\boldsymbol{R}$ Squared $=.308$ (Adjusted $R$ Squared $=.306$ )

\section{PERBINCANGAN}

Kajian menunjukkan sememangnya kaedah mengajar seperti permainan, buku nombor dan lembaran kerja masing-masing dapat membantu meningkatkan pencapaian awal atematik kanak-kanak prasekolah. Namun begitu, pengkaji mendapati kaedah mengajar hanya memberi 
kesan secara signifikan terhadap kefahaman dan analisis awal matematik kanak-kanak prasekolah. Kaedah mengajar yang digunakan tidak memberikan perbezaan pada aras pengetahuan. Perkara ini mungkin disebabkan kanak-kanak mempunyai pengetahuan sedia ada ataupun kaedah mengajar yang dibina mampu menunjukkan pencapaian awal Matematik kanak-kanak pada aras pengetahuan yang lebih kurang sama.

Pengkaji juga mendapati kaedah permainan menunjukkan pencapaian awal matematik kanak-kanak prasekolah yang paling tinggi, diikuti dengan kaedah lembaran kerja dan kaedah buku nombor. Ini berkemungkinan disebabkan kesan latihan dan pemindahan fungsi eksekutif dalam kanak-kanak prasekolah, iaitu bermain permainan yang berulang-ulang boleh meningkatkan ingatan kanak-kanak (Thorell et. al., 2009), membolehkan kanak-kanak memanipulasi alat permainan dan melihat keputusannya (Piaget \& Inhelder, 1969) dan menyediakan persekitaran yang semulajadi dalam membantu perkembangan kanak-kanak (Doig \& Ompok, 2010).

\section{KESIMPULAN}

Pendidik perlu memilih kaedah mengajar awal matematik yang bersesuaian dengan keperluan kanak-kanak. Ini kerana kaedah mengajar memberi kesan terhadap pencapaian awal matematik kanak-kanak prasekolah. Pendidik juga perlu menjadikan kaedah permainan sebagai kaedah mengajar yang utama untuk memastikan kanak-kanak prasekolah dapat menguasai awal matematik dengan baik.

\section{RUJUKAN}

Askew, M., Brown, M., Rhodes, V., Johnson, D., \& William, D. (1997). Effective teachers of numeracy: Final Report Feb 1997. London Kings College.

Baroody, A. J. (1987). Children's mathematical thinking: A developmental framework for preschool, primary, and special education teachers. New York: Teachers College Press.

Bowman, B. T., Donovan, M. S., \& Burns, M. S. (eds). (2001). Eager to learn: Educating our preschoolers. Washington: National Academy Press.

Casey, B. M., Erkut, S., Ceder, I., \& Young, J. M. (2008). Use of a storytelling context to improve girl's and boy's geometry skills in kindergarten. Journal of Applied Developmental Psychology, 29, 29-48.

Chen, J. Q., \& McNamee, G. D. (2011). Positive approaches to learning in the context of preschool classroom activities. Early Childhood Education Journal, 39, 71-78.

Chin, K. E. (2013). Making sense of mathematics: Supportive and problematics conceptions with special reference to trigonometry. A thesis submitted for the degree of Doctor of Philosophy. University of Warwick.

Clarke, B., Baker, S. K., \& Chard, D. J. (2007). Measuring number sense development in young children: A summary of early research. Leadership to Math Success for All, 5, 1-11.

Doig, B. \& Ompok, C. (2010). Assessing child informal mathematic abilities throough games. Mathematics in early childhood. Procedia-Social and Behavioral Sciences, 8, 228-235.

Duncan, G. J., Dowsett, C. J., Claessens, A., Magnuson, K., Huston, A. C., Klebanov, Doabler, C., Baker, S.K., Smolkowski, K., Fien, H., Clarke, B., Cary, M.S., \& Chard, D. (2011). Impact and implementation analyses of the ELM kindergarten Mathematics intervention. SREE Spring 2012 Conference Abstract Template. 
Dunphy, E. (2009). Early childhood Mathematics teaching: Challenges, difficulties and priorities of teachers of young children in primary schools in Ireland. International Journal of Early Years Education, 17(1), 3-16.

Fischetti, J. C. (2013). Issues in education: Last stand for teacher education. Childhood Education, 89(1), 40-41.

Geist, E. (2009). Children are born Mathematicians. Supporting mathematical development, birth to age 8. Columbus: Pearson Education.

Gelman, R., \& Gallistel, C. R. (1978). The child's understanding of number. Cambridge, MA: Harvard University Press.

Gelman, R., \& Meck, E. (1986). The notion of principle: the case of counting. In Hiebert, J. (Ed.). The relationship between procedural and conceptual competence, pp. 24-49. Hillsdale, NJ: Erlbaum Associates.

Ginsburg, H. P., \& Baroody, A. J. (2003). Test of early Mathematics ability ( $3^{\text {rd }}$ edition) Austin: PRO-ED SAGE Publications.

Griffin, S., Case, R., \& Siegler, R. (1994). Rightstart: Providing the central conceptual prerequisites for first formal learning of arithmetic to students at-risk for school failure. In McGilly, K. (Ed.). Classroom lessons: Integrating cognitive theory and classroom practice, pp. 24-49. Cambridge, MA: Bradford Books MIT Press.

Hiebert, J., \& Carpenter, T. P. (1992). Learning and Teaching with Understanding. In Grouws, D. (Ed.) Handbook of research on mathematics teaching and learning, pp. 65-97. New York: MacMillan.

Hiebert, J., \& Lefevre, P. (1986). Conceptual and procedural knowledge in mathematics: An introduction analysis. In Hiebert (Ed.). Conceptual and procedural knowledge: The case for mathematics, pp. 1-27.

Hillsdale. N.J.: Erlbaum.

Hunting, R., Mousley, J. \& Perry, B. (2012). Young children learning mathematics: A guide for educators and families. Melbourne, Vic.: ACER press.

Jeffe, K. (2011). Investment in early childhood care and education. Proceedings: Early childhood care and education: The wealth of the nation. ECEC Council Malaysia and UNICEF.

Koran, L. J., \& McLaughlin, T. F. (1990). Games or drill: Increasing the multiplication skills of students. Journal of Instructional Psychology, 17, 222-230.

Linder, S. M., Powers-Costello, B., \& Stegelin, D. A. (2011). Mathematics in early childhood: Research-based rationale and practical strategies. Early Childhood Education Journal, 39, 29-37.

Piaget, J., \& Inhelder, B. (1969). The psychology of the child. New York: Basic Books.

Ramani, G. B., \& Siegler, R. S. (2008). Promoting broad and stable improvements in lowincome children's numerical knowledge through playing number board games. Child Development, 79(2), 375-394.

Ransom, M. (2012). Choosing a great preschool: A parent's perspective. Childhood Education, 88(4), 266-269.

Rohaty Mohd. Majzub. (2012). Preschool children's early Mathematics achievement based on gender and ethnicity. Asian Social Science, 8(16), 24-29.

Siegler, R. S. (2009). Improving the numerical understanding of children from low-income families. Child Development, 3, 118-124.

Smith, S. S. (2006). Early childhood mathematics ( $3^{\text {rd }}$ edition). Boston: Allyn and Bacon.

Stannard, L., Wolfgang, C. H., Jones, I., \& Phelps, P. (2001). A longitudinal study of the predictive relations among construction play and mathematical achievement. Early Child Development and Care, 167(1), 115-125. 
Starkey, P., Spelke, E. S., \& Gelman, R. (1990). Numerical abstraction by human infants. Cognition, 36(2), 97-127.

Tare, M., Chiong, C., Ganea, P., \& DeLoache, J. (2010). Less is more: How manipulative features affect children's learning from picture books. Journal of Applied Developmental Psychology, 31, 395-400.

Thorell, L., Lindqvist, S., Nutley, S., Bohlin, G., \& Klingbert, T. (2009). Training and transfer effects of executive functions in preschool children. Developmental Science, 12(1), 106-113.

Vygotsky, L. (1966). Play and its role in the mental development of the child. Voprosy Pscyhology, 6(12), 62-76.

Wynn, K. (1992). Addition and subtraction by human infants. Nature, 358, 749-750.

Zhou, X., Huang, J., Wang, Z., Wang, B., Zhao, Z., Yang, L., \& Yang, Z. (2006). Parent-child interaction and children's number learning, early child. Development and Care, 176(7), 763-775.

Zigler, E., Gilliam, W., \& Jones, S. (2006). The case for universal preschool education. New York: Cambridge University Press. 